\title{
Evaluation of Different Germplasms/ Cultivars of Tomato against Early Blight (Alternaria solani) in Field Conditions and by Artificial Inoculation Method: A Review Article
}

\author{
Virendra Kumar', Faiza Naeem², Ajay Kumar ${ }^{3}$ \\ ${ }^{1}$ Regional Pesticides Testing Laboratory, Ministry of Agriculture, Government of India, Department of \\ Agriculture and Co-Operation, Directorate of Plant Protection, Quarantine \& Storage, Kanpur, India \\ ${ }^{2}$ Govt. Raza P.G. College, Rampur, India \\ ${ }^{3}$ Department of Botany, Kashi Naresh Govt. P.G. College, Gyanpur, India \\ Email: drkumarvirendra@gmail.com, faizanaeem.vict@gmail.com, ajaykumarpsr@gmail.com
}

Received 4 June 2015; accepted 18 June 2015; published 24 June 2015

Copyright @ 2015 by authors and OALib.

This work is licensed under the Creative Commons Attribution International License (CC BY).

http://creativecommons.org/licenses/by/4.0/

(c) (i) Open Access

\section{Abstract}

An experiment was conducted for evaluation of tomato germplasm in field conditions and by artificial inoculation method in polyhouse conditions against early blight for two successive years at tomato farm of Swar region of Rampur district during cropping season from February to March. The total 141 tomato germplasms/cultivars were screened, including wild accessions, exotic collection, indigenous cultivars and advanced lines. Among the 141 germplasms, 5 wild accessions viz. EC-520057, EC-520058, EC-520059, EC-52061 and EC-501583 exhibited complete resistant against early blight and 10 lines viz. RCMT-1, LA-40-40-1, KS-118, H-88-78-3, IIVR-Sel-2, H-88-78-1, EC538394, EC-538404, NCEBR-4 and EC-508765 found moderately resistant. The 36 cultivars were found moderately susceptible where disease severity was recorded up to $70 \%$. The 55 cultivars were found to be susceptible and 35 were reported as highly susceptible where disease severity recorded up to $100 \%$ under the field screening. In another set of experiment spore suspension of having the three different cfu levels i.e. 125, 185 and 245 were sprayed on pot experiment under polyhouse conditions on 25 cultivars of tomato to check susceptibility of tomato plant, the higher values of cfu (i.e. $245 \mathrm{cfu}$ ) of $A$. solani were able to break the immunity of plants, in which KDTS-71, DVRT-1-2, CO-3, PANT-T-3 and VFN-8 were found to be highly susceptible to early blight in field screening as well as polyhouse conditions.

\section{Keywords}

Early Blight, Germplasm, Cultivar, Disease Severity, PDI

How to cite this paper: Kumar, V., Naeem, F. and Kumar, A. (2015) Evaluation of Different Germplasms/Cultivars of Tomato against Early Blight (Alternaria solani) in Field Conditions and by Artificial Inoculation Method: A Review Article. Open Access Library Journal, 2: e1548. http://dx.doi.org/10.4236/oalib.1101548 


\section{Introduction}

Early blight is the most important disease of tomato in India and caused by two pathogens i.e. Alternaria solani and Alternaria alternata f. sp. lycopersici. It is also a common problem in United Kingdom, Australia and United States. Symptoms of early blight appear on all above ground parts of the plant. The disease appears first as spots on leaflet; spots are circular to angular, dark brown to black and range from pin head to $4 \mathrm{~mm}$ in diameter. Leaf spots are scattered, brown with conspicuous concentric rings surrounded by chloratic halo on their outer margin due to host specific toxin produced by the pathogen. The stem lesions are usually restricted elongations and sunken. The fruit symptoms initiate generally at the end of February and radiate between attachment of calyx and fruit and are dark brown depressed, firm with distinct concentric rings (Plate 1(b)). Mostly disease appears in vegetative phase of the plant growth before flowering and is more prevalent between flowering to fruit ripening and continue till the crop completely senescent.

Tomato crop is damaged due to severe infection of $A$. solani every year in India. The yield loss of tomato fruit recorded is $78 \%$ at $72 \%$ disease intensity of $A$. solani and each $1 \%$ increase in reduced tomato yield by $1.36 \%$ [1]. The disease severity was recorded up to $90 \%$ [2] in Varanasi region. It is also one of the commonest causes of seedling blight or damping off in tomato, causing dark lesion in rootlets [2]. The genetic resources of all wild species of Lycopersicon spp. have been extensively exploited as resource of early blight resistance. [3] also reported that tomato cultivars CLN-2071, CLN-2070-A BSS-174 and DTH-7 with resistance expressed as slow blightening against four pathogenic isolates of $A$. solani were selected for cultivation in disease prone areas. Diseased intensity increased with the age of plant under same inoculum load. [4] identified the two resistant source lines IIHR-1939 (L. pimpinellifoloum L. 4394) and IIHR-1939 (L. esculentum NCEBR-1). No genetic resource is known within the cultivated species of tomato. However, resistant accessions have been identified within related wild species of tomato, in particular the green fruited species L. hirsutum and the red fruited species L. pimpinellifoloum. A number of control measures were suggested by different researchers for minimizing the disease losses but the use of resistant cultivars remained the most reliable and economical one [5]. Nonjudicial use of fungicides adds human and environmental hazards. Thus, availability of resistant to moderately resistant cultivars may reduce the dependency on fungicides and can also be an effective component of integrated disease management. Therefore the present study was undertaken for the screening of tomato cultivars for incidence of early blight under field condition as well as polyhouse conditions by artificial inoculation method.

\section{Materials and Methods}

\subsection{Field Screening}

The present investigation was carried out during the winter season in Swar region of Rampur District of Uttar Pradesh, India, at tomato farm with total 141 germplasms/cultivars of tomato. The seedlings of tomato were collected from Indian Institute of Vegetable Research (IIVR), Varanasi and were raised separately in nursery and 25 days old tomato seedlings were transplanted in first week of December in both of the successive years. In each plot, 20 seedlings were maintained of each variety with $40 \times 60 \mathrm{~cm}$ spacing. Disease severity of early blight was recorded after 126 days of transplantation. 10 plants from each plot were randomly selected and scored individually using 0 - 5 rating scale based on leaf area, stem and fruit parts covered by blight symptoms. Per cent disease index was recorded as by [6] [7] and [8] were calculated as follows:

The mean value of PDI from first to last observations was also calculated according to [9]. Host plant reaction was classified based on the mean PDI value as highly resistant (0 - 5 rating scale)

$$
\text { PDI }=\frac{\text { Sum of all rating } \times 100}{\text { Total No. of observation } \times \text { Maximum rating grade }} \text {. }
$$

The disease incidence was recorded as by [9]. The data were taken in the month of March on the basis of PDI values. The host plant reaction was classified as resistant (0\%) if no sign of blight symptoms appeared, moderately resistant $(1 \%-25 \%)$ if blight symptoms appeared approx $25 \%$, moderately susceptible if blight symp- 
toms appeared in between (26\% - 50\%), susceptible if symptoms appeared between (51\% - 75\%) and highly susceptible if blight symptoms appeared in between (76\% - 100\%) on above ground parts of the plants. These methodologies were applied for the plants under natural epidemic in field conditions as well as in polyhouse experiment.

\subsection{Screening of Germplasms/Cultivars in Polyhouse Condition}

In order to confirm the immunity of the cultivars an experiment was conducted under polyhouse conditions. In pot experiment, against 25 germplasms/cultivars of tomato (Table 1) at three cfu level of spore suspension of $A$. solani (i.e. 125, 185 and $245 \mathrm{cfu}$ ) were standardized for inoculation purposes. For this purpose five representatives of each cultivar of tomato were taken from each resistant, moderately resistant, moderately susceptible,

Table 1. PDI values of different cultivars at three cfu level under polyhouse condition.

\begin{tabular}{|c|c|c|c|c|}
\hline \multirow{2}{*}{ Cultivars } & \multicolumn{3}{|c|}{ PDI values } & \multirow{2}{*}{ Reaction } \\
\hline & At 125 & At 185 & At 245 & \\
\hline EC-520057 & 0.0 & 0.0 & 0.0 & Resistant \\
\hline EC-520058 & 0.0 & 0.0 & 0.0 & Resistant \\
\hline EC-520059 & 0.0 & 0.0 & 0.0 & Resistant \\
\hline EC-520061 & 0.0 & 0.0 & 0.0 & Resistant \\
\hline EC-520083 & 0.0 & 0.0 & 0.0 & Resistant \\
\hline EC-538154 & 12.0 & 22.0 & 23.0 & Moderately resistant \\
\hline FEB-4-1 & 11.5 & 18.0 & 20.0 & Moderately resistant \\
\hline PDVR-14 & 13.0 & 16.5 & 24.0 & Moderately resistant \\
\hline NCEBR-4 & 10.0 & 13.6 & 18.0 & Moderately resistant \\
\hline H-88-78-5 & 14.0 & 16.5 & 23.5 & Moderately resistant \\
\hline IIVR-Sel-2 & 30.0 & 38.0 & 44.0 & Moderately susceptible \\
\hline H-88-78-1 & 28.0 & 36.0 & 45.0 & Moderately susceptible \\
\hline EC-508765 & 36.0 & 42.0 & 48.5 & Moderately susceptible \\
\hline RCM-1 & 40.5 & 46.0 & 49.0 & Moderately susceptible \\
\hline DVRT-2 & 27.0 & 33.0 & 44.0 & Moderately susceptible \\
\hline Punjab chhuhara & 52.5 & 65.0 & 74.0 & Susceptible \\
\hline Arka-Saurabh & 58.0 & 64.0 & 72.0 & Susceptible \\
\hline IIVR-Sel-3 & 56.0 & 60.5 & 68.5 & Susceptible \\
\hline DARL-63 & 57.5 & 68.5 & 71.5 & Susceptible \\
\hline VLT-34 & 53.5 & 63.3 & 67.3 & Susceptible \\
\hline KDTS-71 & 98.5 & 99.0 & 100.0 & Highly susceptible \\
\hline DVRT-1-2 & 79.3 & 86.5 & 89.0 & Highly susceptible \\
\hline CO-3 & 100.0 & 100.0 & 100.0 & Highly susceptible \\
\hline PANT-T-3 & 78.0 & 88.3 & 98.5 & Highly susceptible \\
\hline VFN-8 & 81.0 & 88.3 & 100.0 & Highly susceptible \\
\hline
\end{tabular}


susceptible and highly susceptible varieties, by previously mentioned methods of screening. Seedlings of the cultivars were raised in pot filled with sterilized soil (Plates 1(c)-(e)). Inoculations were done by different levels of cfu of fungal spore suspension on the one month-old-seedling. Ten days old culture of A. solani was taken to prepare spore suspensions which were isolated from native tomato leaf samples and it was grounded in $50 \mathrm{ml}$ of sterilized distilled water with the help of sterilized pestle and mortar. It was filtered with sterilized muslin cloth in a clean conical flask aseptically. $\mathrm{cfu}_{\mathrm{s}}$ of culture of $A$. solani suspension were measured on Potato dextrose, rose Bengal, agar medium and standardized three different cfu levels. For maintaining the humidity, a humidifier was set up in this chamber around the pot seedlings of tomato and the temperature was maintained for the development of the symptoms. The percent disease incidence was rated as suggested by [9]. The data were taken on $9^{\text {th }}$ day to see the immunity of the different cultivars of tomato.

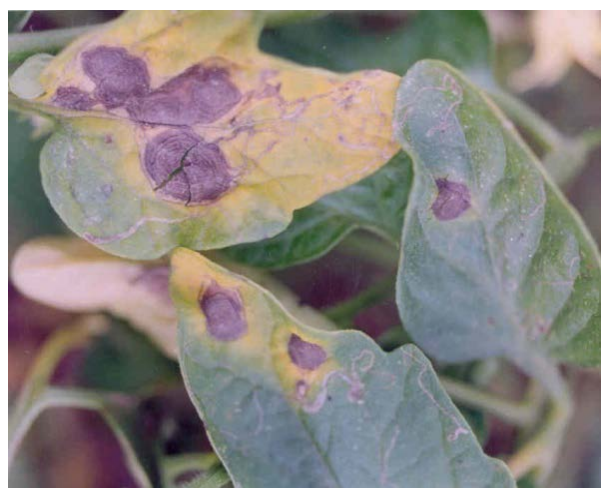

(a)

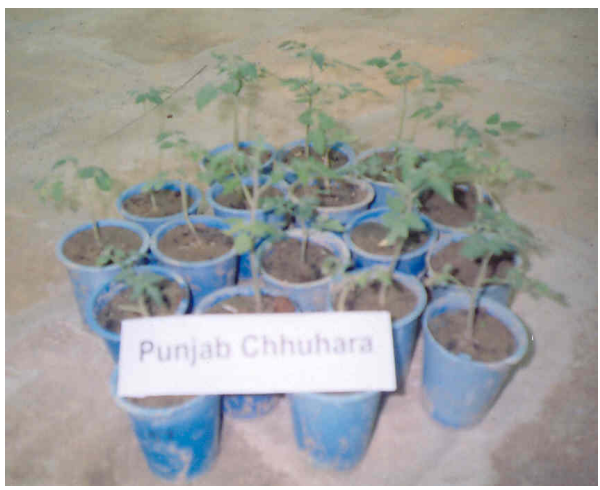

(c)

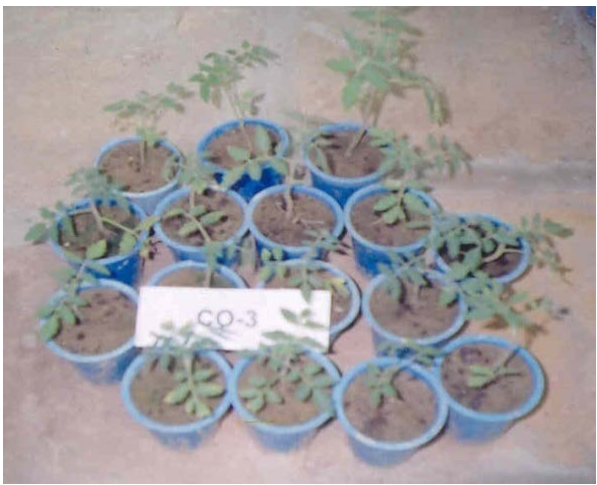

(e)

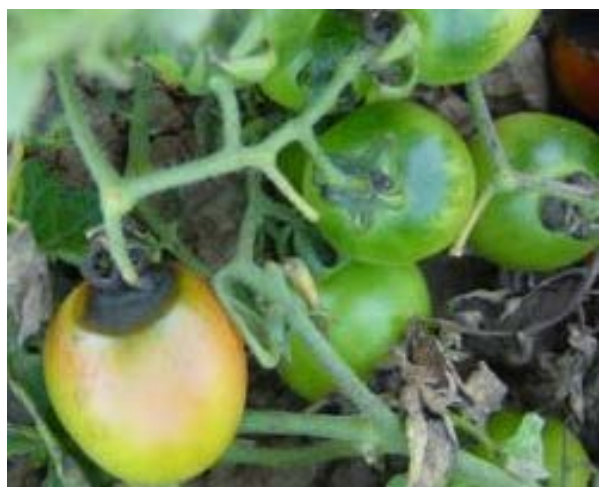

(b)

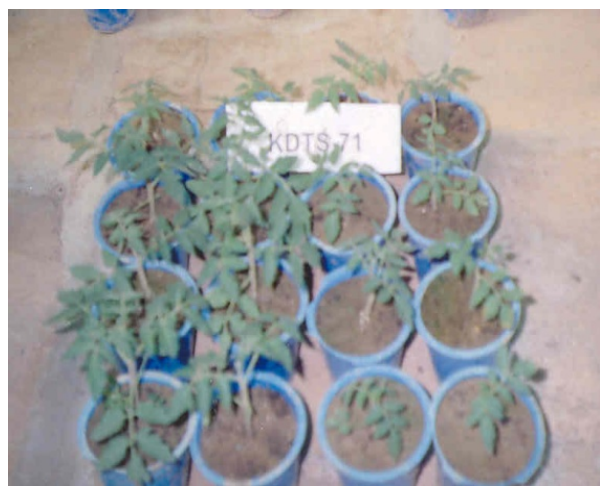

(d)

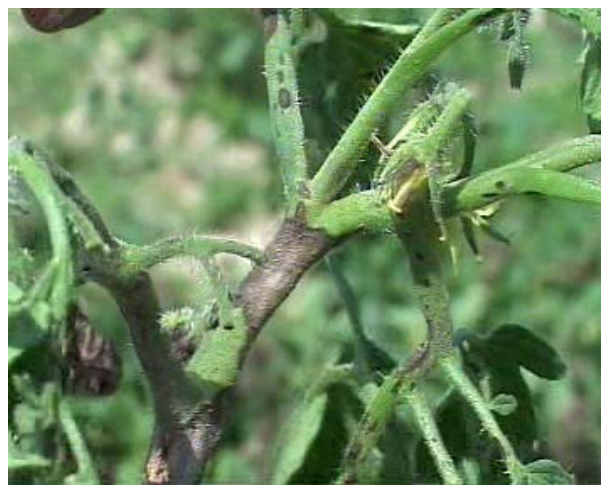

(f)

Plate 1. (a) Circular spot with concentric rings; (b) Apical infection on fruits; (c)-(e) Three susceptible varieties of tomato for pathogenicity test; (f) In vivo infection on tomato as stem girdling with sunken lesion. 


\section{Results}

\subsection{Weather and Disease Development}

Symptoms of early blight were observed within the two week of transplanting as dark brown lesion with concentric rings initially on lower leaves. Stem lesions appeared much later followed by infection on fruits in last week of February (Plate 1(a) \& Plate 1(b)). The disease developed gradually and spread across the whole field assisted by humidity and higher temperature defoliation and infection was more sever in last week of February, when relative humidity (R.H.) were highest up to $89 \%$ in first year. The total rainfall recorded $0.00 \mathrm{~m}$ and temperature $26.7^{\circ} \mathrm{C}$ with 7.2 hrs sunshine was most favourable for the disease development. Therefore the similar observations were recorded in fourth week of February during second year. The total rainfall recorded was 032.2 $\mathrm{m}$ and $26.2^{\circ} \mathrm{C}$ with $7.9 \mathrm{hrs}$ sunshine most favourable for the disease development (Table 2).

\subsection{Reactions of Cultivars to Leaf Blight in Field Screening}

In order to find out the resistant source against the early blight, available cultivars of tomato were screened in natural field conditions and polyhouse conditions, where the disease severity remained very high during the cropping season. Disease severity was recorded using 0 - 5 rating scale on randomly selected plants and finally PDI was calculated for each tomato cultivar. The data was taken 3 times at periodical intervals to see the disease progress of early blight and has been presented in Table 3. Among the 141 genotypes of tomato, the maximum number of cultivars were found highly susceptible, only five lines such as EC-501583, EC-520058, EC-520061, EC-520059, and EC-520057 were found resistant in natural field conditions and ten tomato germplasms i.e. RCM-1, LA-4040, KS-118, H-888-78-3, IIVR-Sel-2, H-8-78-1, EC-538394, EC-538404, NCEBR-4 and EC508765 were found moderately resistant. Thirty six germplasms viz. DVRT-2, VTG-87, DARL-64, SKUAT-2, DT-2, PANT-T-7, JTP-02-7, ATL-97-44, DARL-63, IIVR-SEL-3, VLT-34, BT-120, DT-1, DT-10, ARKA VIKASH, BT-136, NDTS-2002-3, H-86-3, LA-4012-1, F-5013-3, LA-17-1, F-7045-1, F-6012-1, F-701-1, F7025-1, F-5013-4, F-4036-1, F-6050-1, F-6102-1, Punjab Chhuhara, Arka-Saurabh, IST-7, Shalimar, LA-7421, Naptune and Swarna Vaibhav were found to be moderately susceptible in field screening. While fifty five were found to be susceptible and thirty five were found to be highly susceptible in field conditions (Table 3).

\subsection{Reaction of Cultivars to Leaf Blight in Polyhouse Conditions}

The twenty five cultivars of tomato were tested against A. solani at the three cfu levels of spore suspension (i.e. 125, 185 and $245 \mathrm{cfu}$ ) under the polyhouse conditions. Among them the five wild accessions i.e. EC-501583, EC-520058, EC- 520061, EC-520059, and EC-520057 were showing complete resistant and the per cent disease index were recorded as 0\%. The ten cultivars, EC-538154, FEB-4-1, PDVR-14, NCEBR-4, H-88-78-5, IIVRSel-2, H-88-78-1, EC-508765, RCM-1 and DVRT-2 were found to be moderately resistant where the PDI were

Table 2. Agro-meteorological data recorded at Swar region of district Rampur U.P. India, during first year and second year.

\begin{tabular}{|c|c|c|c|c|c|c|c|c|}
\hline \multicolumn{2}{|c|}{ First year } & \multicolumn{2}{|c|}{ Temperature $\left({ }^{\circ} \mathrm{C}\right.$ ) } & \multicolumn{2}{|c|}{ RH (\%) } & \multirow{2}{*}{$\begin{array}{c}\text { Sunshine } \\
\text { Hour }\end{array}$} & \multirow{2}{*}{$\begin{array}{l}\text { Total rainfall } \\
\quad(\mathrm{mm})\end{array}$} & \multirow{2}{*}{$\begin{array}{c}\text { Evaporation } \\
\text { (mm) }\end{array}$} \\
\hline St week & Period & Max & Min & Max & Min & & & \\
\hline 6 & FEB 05-11 & 26.7 & 11.5 & 89 & 58 & 7.2 & 000.0 & 2.3 \\
\hline 7 & FEB 12-18 & 29.5 & 13.7 & 81 & 41 & 9.0 & 000.0 & 2.8 \\
\hline 8 & FEB 19-25 & 31.1 & 15.6 & 76 & 38 & 9.8 & 000.0 & 3.7 \\
\hline 9 & FEB 26-04 & 30.6 & 14.0 & 76 & 36 & 8.0 & 000.0 & 3.3 \\
\hline \multicolumn{9}{|c|}{ Second year } \\
\hline 6 & FEB 05-11 & 22.2 & 13.1 & 89 & 70 & 3.6 & 035.6 & 1.6 \\
\hline 7 & FEB 12-18 & 23.1 & 12.1 & 81 & 55 & 6.2 & 030.6 & 1.9 \\
\hline 8 & FEB 19-25 & 26.1 & 9.9 & 80 & 43 & 10.0 & 001.4 & 2.7 \\
\hline 9 & FEB 26-04 & 26.2 & 13.0 & 80 & 50 & 7.9 & 032.2 & 2.9 \\
\hline
\end{tabular}


recorded up to $10 \%$ - $49 \%$ at all three $\mathrm{cfu}_{\mathrm{s}}$ and five (Punjab chhuhara, Arka-Saurabh, IIVR-Sel-3, DARL-63 and VLT-34) were susceptible where PDI were recorded between $52.5 \%-74 \%$. The five cultivars (KDTS-71, DVRT-1-2, CO-3, PANT-T-3 and VFN-8) were found to be highly susceptible where PDI were recorded in between $78 \%$ - 100\% at all tested cfu levels (Table 1 and Figure 1).

\section{Discussion}

The observations given in the Table 2 clearly reveal that all these test tomato cultivars show resistant (R), moderately resistant (MR), moderately susceptible (MS), susceptible (S) and highly susceptible (HS) reactions at all $\mathrm{cfu}_{\mathrm{s}}$ i.e. at 125, 185 and 245. The third observation was taken from first week of February to last week of February during first and second years and during the periods of high humidity and high temperature conditions

Table 3. Reaction of different germplasm/cultivars against early blight disease of tomato under field condition.

\begin{tabular}{|c|c|c|}
\hline $\begin{array}{l}\text { Mean PDI } \\
\text { value in \% }\end{array}$ & Reaction & Genotype/cultivar (in field) \\
\hline $0 \%$ & $\mathrm{R}$ & EC-501583, EC-520058, EC-520061, EC-520059, and EC-520057 (05) \\
\hline $1 \%-25 \%$ & MR & $\begin{array}{l}\text { RCM-1, LA-4040, KS-118, H-888-78-3, IIVR-Sel-2, H-8-78-1, EC-538394, EC-538404, NCEBR-4 and } \\
\text { EC-508765, (10) }\end{array}$ \\
\hline $26 \%-50 \%$ & MS & $\begin{array}{l}\text { DVRT-2, VTG-87, DARL-64, SKUAT-2, DT-2, PANT-T-7, JTP-02-7, ATL-97-44, DARL-63, IIVR-SEL-3, } \\
\text { VLT-34, BT-120, DT-1, DT-10, ARKA VIKASH, BT-136, NDTS-2002-3, H-86-3, LA-4012-1, F-5013-3, } \\
\text { LA-17-1, F-7045-1, F-6012-1, F-701-1, F-7025-1, F-5013-4, F-4036-1, F-6050-1, F-6102-1, Punjab Chhuhara, } \\
\text { ArkaSaurabh, IST-7, Shalimar, LA-7421, Naptune and Swarna Vaibhav (36) }\end{array}$ \\
\hline $51 \%-75 \%$ & $\mathrm{~S}$ & $\begin{array}{l}\text { KDTS-71, RCMT-2, IMPROVED SHALIMAR-1, DNTS-2002-2, DARL-62, PB UPMA, PANT-T-3, } \\
\text { PDT-3-1-1, VRT-42-1, F-6109-1, F-5010-1, NDTVR-60-1, F-4036-2, EC-519731-1, F-4049-1, H-86-1, } \\
\text { TLH-30-1, F-70111-1, F-6014-2, DVRT-1-1, VRT-40-2, F-5070-2, LA-3947-1, 126PD-1, PDT-3-1, H-86-2, } \\
\text { VRT-1-1, F-6010-1, F-5013-2, LA-4049-1, LA-405-1, F-5013-1, F-6004-1, F-6016-1, VRT-2-1, LA-3951-1, } \\
\text { LA-303-1, VRT-35-1, LA-3997-1, F-40000002-1, F-5025-1, F-6021-1, F-6061-1, VRT-5-1, DVRT-1, F-7028-1, } \\
\text { EC-519785-1, VRT-35-2, LA-3940-1, LA-3941-1, VRT-41-1, IIVR-41-1, IIVR-SEL-3, CH-3, and KS-16 (55) }\end{array}$ \\
\hline $76 \%-100 \%$ & HS & $\begin{array}{l}\text { CO-3, FLB-2-2, EC-519730-1, FEB-4-2, H-88-1, F-6024-1, DVRT-1-2, VRT-32-1, EC-519769-1, F-6059-1, } \\
\text { TLH-27-1, TLH-17-1, LA-3959-1, FEB-4-1, F-4012-1, F-5020-1, TH-806 (F2), H-86, SEL-7, LA-3971-1, } \\
\text { F-4047-1, VRT-4-1, F-505-1, HAT-122-1, VRT-40-1, HAT-18-1, FEB-2-1, LA-3772-1, F-6022-1, PANT-T-3, } \\
\text { F-7012-1, LA-3772-2, VRT-31-1, VFN-8 and EC-538401 (35) }\end{array}$ \\
\hline
\end{tabular}

Where, $\mathrm{R}$ = resistant, MR = moderately resistant, $\mathrm{MS}$ = moderately susceptible, $\mathrm{S}$ = susceptible, HS = highly susceptible.

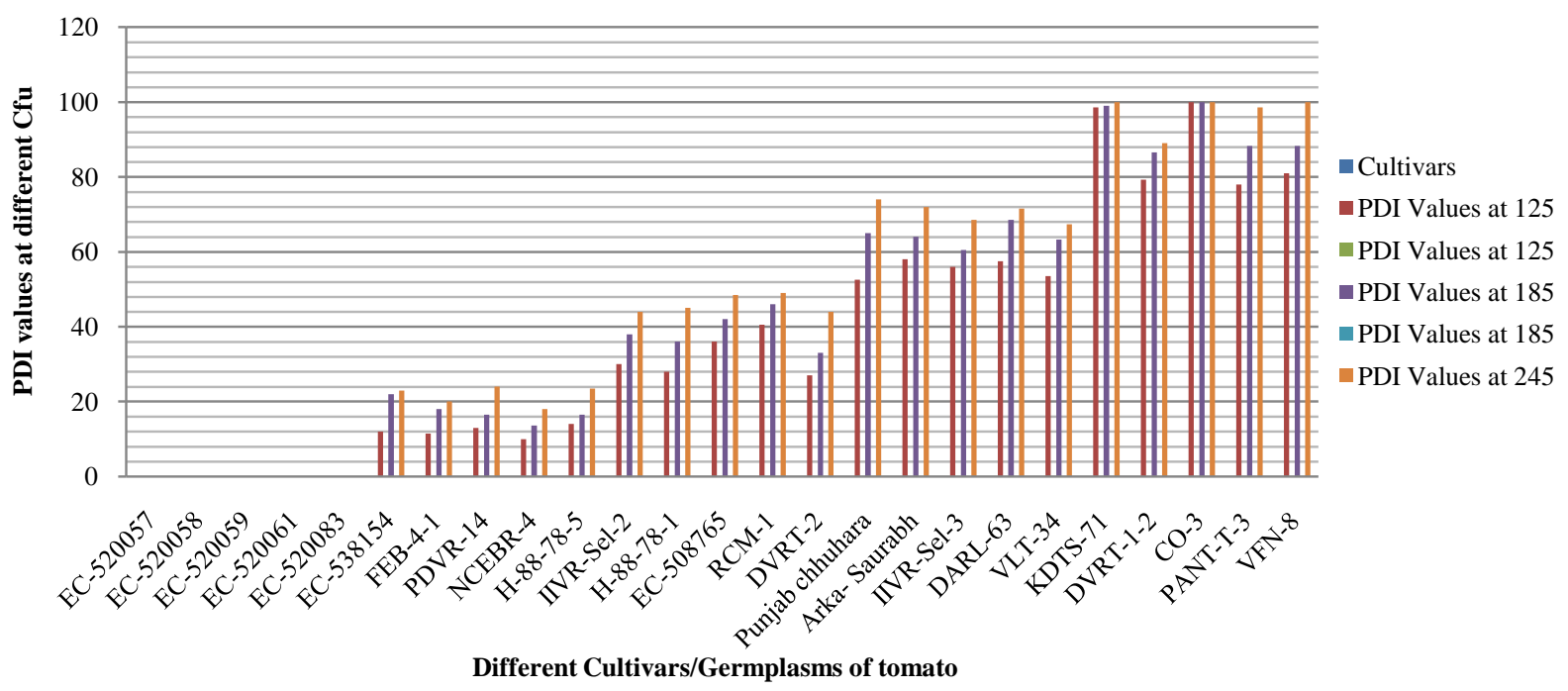

Figure 1. Per cent disease index (PDI) of different tomato cultivars/germplasm at three $\mathrm{cfu}_{\mathrm{s}}$ levels i.e., $125 \mathrm{cfu}, 185 \mathrm{cfu}$ and 245 cfu. 
ranging from $76 \%$ - $89 \%$ R.H. and temperature was in between $26^{\circ} \mathrm{C}-30^{\circ} \mathrm{C}$. High humidity and high temperature were found most congenial for spreading of the disease. So, at high humidity and high temperature disease intensity was recorded very high up to $100 \%$. [10] also reported that when the ambient temperature was near $25^{\circ} \mathrm{C}$ and relative humidity was $96 \%$, the conidia of $A$. solani germinated most rapidly. Therefore, this temperature and humidity were found more suitable for increasing the disease severity. The severity of the disease was recorded $100 \%$ in few cultivars at high cfu value level (cfu 245) in KDTS-71, CO-3 and VFN-8.

[11] observed effect of inoculums concentration of $A$. solani $\left(0.625 ; 1.25 ; 5.0\right.$; and $1 \times 10^{3}$ conidia/ml) on the resistant of tomato cultivars found to be, Santa Clara (Susceptible), CNPH-353, and NCEBR-2 (resistant) under green house conditions. The concentration at $10^{-4}$ conidia/ml made it possible to distinguish resistant and susceptible genotypes of the tomato studied. But our experiment was carried out in its natural epiphytotic condition as well as artificial screening. In a separate experiment, [12] reported that the nine genotypes (Arka-Alok, ArkaAbha, Arka-Meghali, Arka-Sourabh, IIHR-305, IIHR-308, IIHR-2266, IIHR-2285, and IIHR-2288) were resistant, and 11 genotypes were moderately resistant to the pathogen.

An insight into the results obtained revealed that generally, few cultivars showed complete resistant to early blight such as EC-501583, EC-520058, EC-520061, EC-520059, and EC-520057 (wild accessions) in field conditions and the same cultivars were found to be complete resistant in polyhouse conditions; even higher cfu level could not break the immunity of these line. It may be possible because the wild cultivars have some specific genes which are responsible for the resistance, that are needed to be studied. These resources may be utilized to make a resistant variety for plant breeder in future. In polyhouse conditions, we tested the germplasm against three $\mathrm{cfu}_{\mathrm{s}}$ of the pathogen. In this reference we had found that as the inoculums load of fungal spore increased, the PDI also increased but in case of wild accessions there was no effect of inoculums spore load. We are also observed that high humidity (up to $90 \%$ ) and high temperature (up to $25^{\circ} \mathrm{C}-28^{\circ} \mathrm{C}$ ) were the most favourable for disease development. Similar types of observations were recorded by [13] during artificial inoculation of the pathogen in polyhouse conditions. They found tomato cultivars CLN-2071-C, CLN-2070-A, BSS-174 and DTH-41 as slow blighting resistance against four pathogenic isolate of $A$. solani. [9] also conducted the similar experiment with wild accessions. They also found that the eight lines i.e. EC-520057, EC-520059, EC-520061, EC-508765, EC-538394 H-88-78-1 and EC-501583 showed highly resistant reaction against the A. solani, and in our study we also found the similar results. So this confirms the resistant sources and we are supporting the results of [9]. According to [14] the disease intensity was recorded from $21.66 \%$ to $34.48 \%$ but in present research we found 0 to $100 \%$ right from resistant to highly susceptible variety. The similar experiments were also conducted by [15] in natural epidemics. Early blight is strongly influenced by environmental conditions. They had evaluated 44 tomato genotypes against early blight and found the highest early blight incidence in PS-1 (73.56\%) and Kashi Amrit (71.12\%) etc. We have also evaluated DVRT-1-2 (i.e. Kashi Amrit) and the PDI was recorded $89.0 \%$ (Table 3 in HS Category). So this information may be utilized as a resistant source of tomato and may be beneficial to the farmers as a resistant source for tomato farming. The present findings emphasized the need for further evaluation of more number of lines against early blight to find the resistant sample. It should be screened at molecular levels and also it can be used, as a donor source for breeding of disease resistance program in future.

\section{Acknowledgements}

Authors are very much thankful to Dr. K. K. Pandey and Dr. P. K. Pandey, Division of crop protection, IIVR, Varanasi, India for providing different germplasms/cultivars to carry out present research work.

\section{References}

[1] Datar, V.V. and Mayee, C.D. (1985) Chemical Management of Early Blight of Tomato. Journal of Maharashtra Agricultural Universities, 10, 278-280.

[2] Pandey, K.K., Pandey, P.K., Kalloo, G. and Benerjee, M.K. (2003) Resistance to Early Blight of Tomato with Respect to Various Parameters of Disease Epidemics. Journal of General Plant Pathology, 69, 364-371. http://dx.doi.org/10.1007/s10327-003-0074-7

[3] Bose, T.K., Kabir, J., Maithy, T.K., Parthasarathy, V.A. and Som, M.G. (2002) Vegetable Crops. Vol. 1, 1-154.

[4] Thirthamallappa and Lohithaswa, H.C. (2000) Genetic and Resistance to Early Blight in Tomato. Euphytica, 13, 187-193. http://dx.doi.org/10.1023/A:1003929303632 
[5] Keinath, A.A., DuBose, V.B. and Rathwell, P.J. (1996) Efficacy and Economics of Three Fungicidal Application Schedule for Early Blight and Yield of Fresh Market Tomato. Plant Disease, 80, 1277-1282. http://dx.doi.org/10.1094/PD-80-1277

[6] Shaner, G. and Finney, R.E. (1977) The Effect of Nitrogen Fertilization on the Expression of Slow Mildewing Resistance in Knox Wheat. Phytopathology, 67, 1051-1056. http://dx.doi.org/10.1094/Phyto-67-1051

[7] Johnson, D.A. and Wilcoxon, R.D. (1982) A Table of Area under Disease Progress Curve. Technical Bulletin, Texas Agriculture Experiment Station, Texas, 122 p.

[8] Campbell, C.L. and Wilcoxon, L.V. (1982) Introduction to Plant Disease Epidemiology, John Wiley and Sons Inc. New York, 165 p.

[9] Prabhash, C.S., Rajesh, K., Major, S., Ashutosh, R., Singh, M.C. and Mathura, R. (2011) Identification of Resistant Sources against Early Blight Disease of Tomato. Indian Journal of Horticulture, 68, 516-521.

[10] Virendra, K., Sanchita, H., Koshlendra, K.P., Rana, P.S., Achuit, K.S. and Prabhas, C.S. (2008) Cultural, Morphological, Pathogenic and Molecular Variability amongst Tomato Isolates of Alternaria solani in India. World Journal of Microbiology and Biotechnology, 24, 1003-1009. http://dx.doi.org/10.1007/s11274-007-9568-3

[11] Stevenson, R.E. and Pennypacker, S.P. (1988) Effect of Radiation, Temperature, and Moisture on Conidial Germination of Alternaria solani. Phytopathology, 78, 926-930. http://dx.doi.org/10.1094/Phyto-78-926

[12] Castro, M.E.A., Chaves, G.M., Zambolim, L., Cruz, C.D. and Silva, D.J.H. (1999) Effect of Inoculums Concentration on the Resistance of Tomato to Alternaria solani. Fitopathologia Brasileira, 24, 463-465.

[13] Prasad, Y. and Naik, M.K. (2003) Evaluation of Genotypes, Fungicides, and Plant Extracts against Blight of Tomato Caused by Alternaria solani. Indian Journal of Plant Protection, 31, 49-53.

[14] Sunita, R., Ranbir, S., Sachin, G., Siddarth, D. and Razdan, V.K. (2015) Identification of Resistant Sources and Epidemiology of Early Blight (Alternaria solani) of Tomato (Lycopersicon esculentum) in Jammu and Kashmir. Indian Phytopathology, 68, 87-92.

[15] Sunil, K. and Kartikeya, S. (2013) Screening of Tomato Genotypes against Early Blight (Alternaira solani) under Field Condition. The Bioscan, 8, 189-193. 